\title{
Prevalence and socio-demographic correlates of physical activity levels among South African adults in Cape Town and Mount Frere communities in 2008-2009
}

Pasmore Malambo ${ }^{1 *}$, Andre P. Kengne ${ }^{2}$, Estelle V. Lambert ${ }^{3}$, Anniza De Villiers $^{2}$ and Thandi Puoane ${ }^{1}$

\begin{abstract}
Background: Physical activity has been linked to reduced risk of various cardiometabolic disease, cancer, and premature mortality. We investigated the prevalence and socio-demographic correlates of physical activity among adults in urban and rural communities in South Africa. Methods: This was a cross-sectional survey comprising 1733 adults aged $\geq 35$ years from the Cape Town (urban) and Mount Frere (rural) sites of the Prospective Urban Rural Epidemiology study. Physical activity was assessed using the validated International Physical Activity Questionnaire. Multinomial logistic regressions were used to relate physical activity with socio-demographic characteristics.

Results: Overall, $74 \%$ of participants engaged in moderate-to-vigorous physical activity. In the adjusted regression models, women were $34 \%$ less likely to engage in vigorous physical activity $(\mathrm{OR}=0.66,95 \%-\mathrm{Cl}=0.47-0.93)$. Physical activity decreased with age, varied with marital status, education and occupation, always in differential ways between urban and rural participants (all interactions $p \leq 0.047$ ). For instance, in urban settings, those with secondary education were more likely to engage in moderate physical activity $(\mathrm{OR}=2.06,95 \%-\mathrm{Cl}=1.08-3.92)$ than those with tertiary education. Single people were more likely to engage in high physical activity $(O R=2.10$, $95 \%-\mathrm{Cl}=1.03-4.28)$ than divorced. Overall, skilled participants were more likely to engage in vigorous physical activity $(\mathrm{OR}=2.07,95 \%-\mathrm{Cl}=1.41-3.05)$ driven by significant effect in rural area $(\mathrm{OR}=2.70,95 \%-\mathrm{Cl}=1.51-4.83)$. Urban participants were more likely to engage in moderate physical activity $(\mathrm{OR}=1.67,95 \%-\mathrm{Cl}=1.31-2.13)$ than rural participants.
\end{abstract}

Conclusions: To prevent chronic diseases among South Africans, attention should be paid to specific policies and interventions aimed at promoting PA among young adults in rural and urban setting, and across the social-economic diversity.

Keywords: Physical activity, Socio-demography, Determinants, Rural, Urban, Adult, Non-communicable diseases, South Africa

\footnotetext{
* Correspondence: pmalambo@hotmail.com

${ }^{1}$ University of Western Cape, School of Public Health, Robert Sobukwe Road,

Bellville, Cape Town 7535, South Africa

Full list of author information is available at the end of the article
} 


\section{Background}

The health benefits of physical activity (PA) in the prevention and control of non-communicable diseases (NCDs) are well established [1]. Participation rates in PA, however, remain low in all age groups [2]. For example, more than $60 \%$ of adults worldwide do not reach recommended 150 min weekly of moderate PA required to be of benefit to their health $[3,4]$. It is estimated that physical inactivity defined as any activity insufficient to meet current global recommendations [5], indirectly causes $9 \%$ of premature mortality; it was linked to approximately 1.3 million of the 57 million deaths that occurred worldwide in 2008 [4]. For instance, physical inactivity could account for $6 \%$ of coronary heart disease, $7 \%$ of type 2 diabetes and $10 \%$ of cancer [4], making it the fourth leading cause of NCDs [3]. In South Africa, 3.3\% of all deaths in 2000 were attributable to PA, ranking it $9^{\text {th }}$ among other risk factors [6]. The prevalence of self-reported physical inactivity is high in both developed countries like the United States, where $32 \%$ of adults are physically inactive [7], and in developing countries such as South Africa were 45\% adults were reported to be inactive [8]. Other African countries also report a high prevalence of physical inactivity among adults, $49.1 \%$ and $52.6 \%$ in Swaziland and Mauritania respectively [8].

Similar to other developing countries, South Africa is currently undergoing nutritional, lifestyle, and socioeconomic transitions, with increases in the occurrence of NCDs [9]. Non-communicable diseases of lifestyle share similar modifiable risk factors, which include hypertension, tobacco smoking, diabetes, obesity, hyperlipidaemia and physical inactivity [10]. Physically inactivity in global populations represents a major public health challenge [4]. Documented research comparing activity levels in urban and rural settings suggests that rural adults tend to be less active than their urban counterparts, although findings have been inconsistent [11]. In the USA, a study revealed that PA levels were higher in urban areas than in rural areas [12]. Similarly, in South Africa, subjects in isolated rural areas were found to be more inactive than their urban-dwelling counterparts [10]. Again, similar results were also reported in a study of Kenyan adolescents [13]. Conversely, a South African Demographic and Health Survey found that urban youths were more likely to be physically inactive than rural ones [14].

The importance of promoting physical activity in populations is reflected by the South Africa National Strategic Plan for the Prevention and Control of noncommunicable diseases, which targets a $10 \%$ reduction in the prevalence of inactivity by 2020 [15]. Indeed, a recommendation for every adult to accumulate $30 \mathrm{~min}$ or more of moderate-intensity physical activity on as many days and, preferably, every day of the week [16] is estimated to increase the life expectancy of the world's population [4].

However, in order to understand PA patterns and make positive changes to them, it is important to understand the independent contributions of urbanrural and socio-demographic risk factors [17]. Conducting population-based studies on prevalence of physical activity and its determinants is necessary to identify the relevant areas in local environments that need change, areas where currently such information is scarce [18]. In this study, we determine the prevalence of self-reported PA and associated socio-demographic factors among South African adults in urban and rural communities.

\section{Methods}

\section{Study population}

This cross-sectional study uses data from the Cape Town (urban) and Mount-Frere (rural) sites of the global Prospective Urban and Rural Epidemiology study (PURE) study. PURE is a multinational cohort study that tracks societal influences, risk factors and chronic noncommunicable diseases in urban and rural areas across 17 countries including South Africa. PURE collects baseline data on countries' characteristics (e.g. economic environments), communities (e.g. nutritional environment), households (e.g. income) and individual determinants (e.g. diet and physical activity) [19]. During a baseline evaluation conducted by PURE in 2008-2009, a representative random sample of adults was selected from well-established rural (Mount Frere) and urban (formal settlements in Cape Town) communities in South Africa. The household inclusion criteria were: (1) to have at least one member who was aged 35-70 years, (2) to be within an identified neighbourhood and (3) to not have members with a disability that precluded walking.

\section{Data collection}

Participants were interviewed in the language of their choice. We used structured, socio-demographic and lifestyle questionnaires that were developed and standardized for the international PURE study [19]. Physical examination included anthropometric measures (height, weight, waist and hip circumference) [20]. In all consenting and eligible individuals, the long version of the International Physical Activity Questionnaire (IPAQ) was used to measure self-reported PA [21].

\section{Socio-demographic characteristics}

We recorded socio-demographic information, specifically: age, sex, marital status, education level, and occupation from each participant. We grouped them into four age categories: 35 to 44 years, 45 to 54 years, 
55 to 64 years and 65 years or older. Marital status was classified as never married, currently married, and widowed/divorced/separated. Education level was classified as primary, secondary and tertiary education. Occupational status ranged from 1 to 11 items prompted by the following statement; "Please indicate which group best describes your main occupation". In this study, the occupation status was then categorized as skilled (technicians, machine operators, clerks, skilled agriculture and fishery workers) and less skilled (homemaker, service, shop and market workers).

\section{Physical activity measure}

The IPAQ includes questions on frequency and duration of vigorous and moderate intensity physical activities, and walking in terms of the frequency (days/week) and duration ( $\mathrm{min} /$ day) in the last 7 days. The physical activities were classified into the domains of work-related, transport-related, household-related and leisure activity for each category of walking, moderate and vigorousintensity. Weekly minutes of walking, moderate-intensity and vigorous-intensity activity were calculated separately by multiplying the number of days/week by the duration on an average day. In this study, physical activity levels were classified as low, moderate, or high intensity, defined by the IPAQ core group (http://www.ipaq.ki.se) as follows: Low - no activity or some activity reported, but not enough to satisfy the requirements of the other activity categories; Moderate - any of the following 3 criteria: (a) 3 or more days of vigorous-intensity activity for at least 20 min per day, (b) 5 or more days of moderate intensity activity or waking for at least $30 \mathrm{~min}$ per day, or (c) 5 or more days of any combination of walking, moderate intensity, or vigorous-intensity activities achieving a minimum of 600 MET-minutes per week; Vigorous - either of the following 2 criteria: (a) 3 or more days of vigorous-intensity activity accumulating at least 1500 MET-minutes per week or (b) 7 days of any combination of walking or moderate- or vigorous intensity activities achieving a minimum of 3000 METminutes per week. Acceptable reliability and validity of IPAQ has been reported elsewhere [22].

\section{Statistical analysis}

The starting sample comprised 2064 participants of whom 316 were excluded for unacceptable levels of missing data [23]. A further 15 participants aged less than 35 years were excluded, making a final analytic sample of 1733 participants. We used SPSS ${ }^{\oplus}$ version 22 for Windows (IBM Corp: Armonk New York) for all statistical analyses. Chi squared tests were used to compare socio-demographic characteristics and physical activity. We used multinomial logistic regressions to investigate the determinants of physical activity, with low physical activity as the reference, both in univariate and multivariate models. The differential effects of socio-demographic characteristics on physical activity levels according to urban and rural setting were assessed through interaction tests. Statistical significance was set at $p<0.05$.

\section{Results}

General characteristics and pattern of physical activity

Table 1 shows the overall and site-specific (urban/rural), socio-demographic characteristics and the prevalence of

Table 1 Socio-demographic characteristics of adults South Africans from Cape Town and Mount Frere communities in 2008-2009

\begin{tabular}{|c|c|c|c|c|}
\hline \multirow[t]{2}{*}{ Variables } & $\begin{array}{l}\text { Urban } \\
(n=877)\end{array}$ & $\begin{array}{l}\text { Rural } \\
(n=856)\end{array}$ & $P$-value & \multirow{2}{*}{$\begin{array}{l}\text { Overall } \\
(N=1733 \\
(\%)\end{array}$} \\
\hline & (\%) & (\%) & & \\
\hline Gender & & & 0.011 & \\
\hline Female & 71.4 & 76.8 & & 74.0 \\
\hline Male & 28.6 & 23.2 & & 26.0 \\
\hline Age & & & 0.375 & \\
\hline $35-44$ & 30.1 & 31.5 & & 30.8 \\
\hline $45-54$ & 35.0 & 31.1 & & 33.1 \\
\hline $55-64$ & 26.0 & 27.6 & & 26.8 \\
\hline 65 and above & 8.9 & 9.8 & & 9.3 \\
\hline $\mathrm{BMI}\left(\mathrm{kg} / \mathrm{m}^{2}\right)$ & & & $<0.001$ & \\
\hline$<18.5$ & 3.7 & 2.8 & & 3.2 \\
\hline $18.5-24.9$ & 21.1 & 28.2 & & 25.3 \\
\hline $25.0-29.9$ & 18.2 & 27.3 & & 23.6 \\
\hline$>30.0$ & 57.0 & 41.7 & & 47.9 \\
\hline Education level & & & $<0.001$ & \\
\hline Primary & 23.8 & 49.9 & & 36.7 \\
\hline Secondary & 69.1 & 47.3 & & 58.3 \\
\hline Tertiary & 7.1 & 2.8 & & 5.0 \\
\hline Marital status & & & $<0.001$ & \\
\hline Single & 51.2 & 30.8 & & 41.1 \\
\hline Currently married & 33.6 & 44.7 & & 39.1 \\
\hline $\begin{array}{l}\text { Widowed/divorced/ } \\
\text { separated }\end{array}$ & 15.2 & 24.4 & & 19.7 \\
\hline Occupation & & & $<0.001$ & \\
\hline Skilled & 22.2 & 14.6 & & 18.5 \\
\hline Less skilled & 77.8 & 85.4 & & 81.5 \\
\hline Ethnicity & & & 0.693 & \\
\hline African & 98.7 & 98.9 & & 98.8 \\
\hline Coloured & 1.3 & 1.1 & & 1.2 \\
\hline Physical activity levels & & & $<0.001$ & \\
\hline Low & 20.9 & 31.0 & & 25.9 \\
\hline Moderate & 61.2 & 51.5 & & 56.4 \\
\hline Vigorous & 17.9 & 17.5 & & 17.7 \\
\hline
\end{tabular}


PA among the participants. Participants were evenly divided between urban (50.6\%) and rural (49.4\%) sites. Women comprised the majority of the sample in rural (76.8\%) and urban (71.4\%) sites and overall (74\%) and their proportional was significantly higher than that of men $(p=0.011)$. The most common age group was 45 54 years $(33.1 \%)$, and age distribution did not differ across sites $(p=0.375)$. Obesity $\left(B M I \geq 30 \mathrm{~kg} / \mathrm{m}^{2}\right)$ was higher in the urban site at $57 \%$, versus $42 \%$ in the rural site and differences were significant $(p<0.001)$. There were significant differences between urban and rural sites for categories of education, marital status and occupation (all $p<0.001$ ), Table 1. Patterns of PA were $31 \%$, $51.5 \%$ and $17.5 \%$ in the rural site; $20.9 \%, 61.2 \%$ and $17.9 \%$ in the urban site and $25.9 \%, 56.4 \%$ and $17.7 \%$ in combined sites for low, moderate and vigorous PA respectively in each case, and differences between sites were significant $(p<0.001)$, Table 1 .

\section{Socio-demographic characteristics and physical activity levels}

Table 2 shows the PA patterns for each sociodemographic category. Overall, gender, age, education level, marital status, occupation and location were significantly associated with physical activity $(p<0.01)$. In stratified analysis, the pattern of PA differed between men and women in the rural site $(p=0.031)$, but not the urban site $(p=0.371)$. The prevalence of vigorous physical activity decreased with increased age group in rural area $(p<0.001)$, and a borderline difference in the

Table 2 Socio-demographic characteristics by physical activity levels among adults South Africans from Cape Town and Mount Frere communities in 2008-2009

\begin{tabular}{|c|c|c|c|c|c|c|c|c|c|c|c|c|}
\hline \multirow[t]{2}{*}{ Variables } & \multicolumn{4}{|c|}{$\begin{array}{l}\text { Urban ( } n=877 \text { ) } \\
\text { Physical activity }\end{array}$} & \multicolumn{4}{|c|}{$\begin{array}{l}\text { Rural ( } n=856) \\
\text { Physical activity }\end{array}$} & \multicolumn{4}{|c|}{$\begin{array}{l}\text { Overall }(N=1733) \\
\text { Physical activity }\end{array}$} \\
\hline & $\begin{array}{l}\text { Low } \\
(\%)\end{array}$ & $\begin{array}{l}\text { Moderate } \\
(\%)\end{array}$ & $\begin{array}{l}\text { Vigorous } \\
(\%)\end{array}$ & $P$-value & $\begin{array}{l}\text { Low } \\
(\%)\end{array}$ & $\begin{array}{l}\text { Moderate } \\
(\%)\end{array}$ & $\begin{array}{l}\text { Vigorous } \\
(\%)\end{array}$ & $P$-value & $\begin{array}{l}\text { Low } \\
(\%)\end{array}$ & $\begin{array}{l}\text { Moderate } \\
(\%)\end{array}$ & $\begin{array}{l}\text { Vigorous } \\
(\%)\end{array}$ & $P$-value \\
\hline Gender & & & & 0.371 & & & & 0.031 & & & & 0.014 \\
\hline Women & 21.4 & 61.8 & 16.8 & & 32.1 & 52.2 & 15.7 & & 26.9 & 56.9 & 16.2 & \\
\hline Men & 19.5 & 59.8 & 20.7 & & 27.1 & 49.2 & 23.6 & & 22.9 & 55.1 & 22.0 & \\
\hline Age & & & & 0.057 & & & & $<0.001$ & & & & $<0.001$ \\
\hline $35-44$ & 20.5 & 62.1 & 17.4 & & 25.6 & 48.8 & 25.6 & & 23.0 & 55.4 & 21.5 & \\
\hline $45-54$ & 19.9 & 59.0 & 21.2 & & 27.1 & 57.1 & 15.8 & & 23.2 & 58.1 & 18.7 & \\
\hline $55-64$ & 18.9 & 63.6 & 17.5 & & 33.1 & 53.0 & 14.0 & & 26.1 & 58.2 & 15.7 & \\
\hline 65 and above & 32.1 & 60.3 & 7.7 & & 54.8 & 38.1 & 7.1 & & 43.8 & 48.8 & 7.4 & \\
\hline $\mathrm{BMI}\left(\mathrm{kg} / \mathrm{m}^{2}\right)$ & & & & 0.850 & & & & 0.314 & & & & 0.463 \\
\hline$<18.5$ & 29.4 & 52.4 & 17.6 & & 21.1 & 63.0 & 15.9 & & 25.0 & 58.3 & 16.7 & \\
\hline $18.5-24.9$ & 20.8 & 57.3 & 21.9 & & 29.5 & 52.6 & 17.9 & & 26.6 & 54.2 & 19.2 & \\
\hline $25.0-29.9$ & 20.5 & 61.4 & 18.1 & & 33.7 & 55.4 & 10.9 & & 29.6 & 57.3 & 13.1 & \\
\hline$>30.0$ & 17.3 & 63.5 & 19.2 & & 32.4 & 49.1 & 18.5 & & 25.1 & 56.0 & 18.9 & \\
\hline Education level & & & & 0.009 & & & & 0.167 & & & & 0.003 \\
\hline Primary & 24.4 & 63.6 & 12.0 & & 33.5 & 50.8 & 15.7 & & 30.5 & 55.0 & 14.5 & \\
\hline Secondary & 18.6 & 61.9 & 19.5 & & 29.4 & 51.6 & 19.0 & & 22.9 & 53.8 & 19.3 & \\
\hline Tertiary & 30.6 & 46.8 & 22.6 & & 12.5 & 62.5 & 25.0 & & 25.6 & 51.2 & 23.3 & \\
\hline Marital status & & & & 0.010 & & & & 0.086 & & & & $<0.001$ \\
\hline Single & 17.1 & 61.7 & 21.2 & & 28.8 & 51.1 & 20.1 & & 21.5 & 57.8 & 20.8 & \\
\hline Married & 23.1 & 61.7 & 15.3 & & 29.2 & 52.0 & 18.8 & & 26.5 & 56.2 & 17.3 & \\
\hline Divorced/separated & 28.6 & 58.6 & 12.8 & & 36.8 & 51.2 & 12.0 & & 33.6 & 54.1 & 12.3 & \\
\hline Occupation & & & & $<0.001$ & & & & $<0.001$ & & & & $<0.001$ \\
\hline Skilled & 21.0 & 51.8 & 27.2 & & 20.0 & 48.0 & 32.0 & & 20.6 & 50.3 & 29.1 & \\
\hline Less skilled & 20.8 & 63.9 & 15.2 & & 32.8 & 52.1 & 15.0 & & 27.0 & 57.8 & 15.1 & \\
\hline Location & & & & & & & & & & & & $<0.001$ \\
\hline Urban & & & & & & & & & 20.9 & 61.2 & 17.9 & \\
\hline Rural & & & & & & & & & 31.0 & 51.5 & 17.5 & \\
\hline
\end{tabular}


distribution of PA across age groups in the urban site ( $p=$ $0.057)$. Education levels in urban area was positively associated with vigorous PA $(p=0.009)$, but not in the rural one $(p=0.161)$. This pattern was different for marital status in the urban site $(p=0.010)$, but not in the rural site $(p=0.086)$. The pattern with occupation was mostly similar and differences were significant when stratified by site $(p<0.001$ in both sites), Table 2.

\section{Multivariable regression analysis and interaction tests}

Table 3 shows odds ratios from age and sex-adjusted multinomial regression analyses of socio-demographic characteristics and PA. In these models, when applied to all participants, age $(p<0.001)$, occupation $(p<0.001)$,) and location $(p<0.001)$ were significantly associated with PA level, while there was a borderline association with gender $(p=0.055)$, and no association with education $(p=0.116)$ or marital status $(p=0.126)$, Table 3 . With the exception of gender $(p=0.072)$, significant interactions were observed between location and sociodemographic characteristics (results not shown in the table), in their relationship with PA $(p<0.001$ for age"location, $p=0.012$ for education level"location, $p<0.001$ for marital status*location, $p<0.001$ for occupation"location interaction tests).

Overall, women were $34 \%$ less likely $(\mathrm{OR}=0.66,95 \%$ $\mathrm{CI}=0.47-0.95)$ to engage in vigorous PA than men. The odds of engaging in vigorous PA decreased with increasing age, with the effects being significant across age strata overall and in urban and rural participants. Each age category was more likely to engage in moderate and vigorous PA than those in the category aged 65 and above, in both the overall cohort and in rural participants, but not in the urban ones $(p<0.001$ for age*location interaction). Having a secondary education (relative to tertiary) was associated with an OR of 2.06 (95\% CI = 1.08-3.92) for engaging in moderate PA among urban participants only.

Marital status was variably associated with PA in the overall cohort and across sites $(p<0.001$ for the interaction marital status"location). For instance, single participants (relative to those divorced) were more likely to engage in vigorous PA in the overall cohort and in the urban site, Table 3.

In the overall cohort, skilled participants (relative to less skilled) were associated with higher odds of engaging in vigorous PA. The effect was similar in both rural and urban participants $(p<0.001$ for occupation*location interaction).

\section{Discussion}

This study provides insight into the socio-demographic correlates of PA levels in the urban and rural communities of South African adults. Over half the participants sampled engaged in moderate to high PA. However, a higher proportion of physical inactivity was observed in the rural participants compared to those in urban areas. Urban participants were more likely to meet recommended PA guidelines for public health than their rural counterparts. Similarly, the odds of participants achieving recommended PA guidelines (moderate PA) were $76 \%$ higher in an urban than in a rural setting. The results of this study can be compared with the findings of a PA survey from 22 African countries where prevalence of PA ranged from $72.5 \%$ (Swaziland) to $96.0 \%$ (Mozambique) [8]. Similarly, 67\% of urban dwelling black South African women were classified as physically active [24]. Conversely, the odds of participants being physically inactive in United States was $43 \%$ higher in the extreme rural areas compared with urban ones [12]. A study in Cameroon, however, showed that rural dwellers were significantly more active than their urban counterparts based on objectively measured physical activity [25].

A high prevalence of physical inactivity in rural areas, especially in South Africa, may be because PA is largely of low intensity there. A study conducted in KwaZulu-Natal in South Africa reported high volumes of low intensity physical activity among rural children and adolescents [26]. It is also stated that the spread of technology used across different domains of society and the shift in the predominant type of employment and lifestyle behaviour, specifically from agriculture to industries and services, contributed to a reduction in physical activity [27]. The variations of results across studies could be due to different tools used to measure physical activity. In addition, there is difficulty to understand the intent of the IPAQ questions, in recalling the information requested, and in making the calculations required to perform physical activity [28]. Furthermore, different types of PA are undertaken between and within communities that are socially, economically, geographically and religiously different across aspects of life [29]. For this reason, objective assessment of physical activity would provide more insight in the levels and patterns of physical activity in South African population. Therefore, results of the current study are interpreted with caution.

The overall prevalence of moderate to vigorous physical activity did not differ significantly between genders. However, the adjusted odds ratio showed that women were $34 \%$ less likely to engage in the vigorous PA than men. A similar study found that women exhibited higher levels of inactivity than men and that inactivity was higher among older people [8]. Concurrently, a study conducted in Spain reported comparable results [30]. Conversely, studies conducted in Rwanda [31] and Nigeria [17], showed a higher prevalence of PA among women than in men. 
Table 3 Multinomial logistic regression result of socio-demographic characteristics by physical activity levels with reference to low physical activity in adults South Africans from Cape Town and Mount Frere communities in 2008-2009

\begin{tabular}{|c|c|c|c|c|c|c|c|c|c|c|c|c|c|c|c|}
\hline \multirow[t]{3}{*}{ Variables } & \multicolumn{4}{|c|}{$\begin{array}{l}\text { Urban }(n=877) \\
\text { Physical activity }\end{array}$} & \multirow[t]{3}{*}{$p$-value } & \multicolumn{4}{|c|}{$\begin{array}{l}\text { Rural }(n=856) \\
\text { Physical activity }\end{array}$} & \multirow[t]{3}{*}{$p$-value } & \multicolumn{4}{|c|}{$\begin{array}{l}\text { Overall (N=1733) } \\
\text { Physical activity }\end{array}$} & \multirow[t]{3}{*}{$p$-value } \\
\hline & \multicolumn{2}{|c|}{ Moderate } & \multicolumn{2}{|c|}{ Vigorous } & & \multicolumn{3}{|c|}{ Moderate } & \multirow{2}{*}{$\begin{array}{l}\text { Vigorous } \\
95 \%-\mathrm{Cl}\end{array}$} & & \multicolumn{2}{|c|}{ Moderate } & \multicolumn{2}{|l|}{ Vigorous } & \\
\hline & $\overline{\mathrm{OR}^{a}}$ & $95 \%-\mathrm{Cl}$ & $\overline{\mathrm{OR}^{a}}$ & $95 \%-\mathrm{Cl}$ & & $\overline{\mathrm{OR}^{\mathrm{a}}}$ & $95 \%-\mathrm{Cl}$ & $O R^{a}$ & & & $\overline{\mathrm{OR}^{a}}$ & $95 \%-\mathrm{Cl}$ & $\overline{\mathrm{OR}^{a}}$ & $95 \%-\mathrm{Cl}$ & \\
\hline Gender & & & & & 0.351 & & & & & 0.154 & & & & & 0.050 \\
\hline Men & 1.00 & & 1.00 & & & 1.00 & & 1.00 & & & 1.00 & & 1.00 & & \\
\hline Women & 0.89 & $0.61-1.32$ & 0.71 & $0.44-1.14$ & & 0.91 & $0.62-1.35$ & 0.63 & $0.38-1.01$ & & 0.91 & $0.69-1.19$ & $0.66^{*}$ & $0.47-0.93$ & \\
\hline Age & & & & & 0.360 & & & & & $<0.001$ & & & & & $<0.001$ \\
\hline 65 and above & 1.00 & & 1.00 & & & 1.00 & & 1.00 & & & 1.00 & & 1.00 & $2.07-8.13$ & \\
\hline $35-44$ & 1.40 & $0.75-2.61$ & 2.31 & $0.83-6.44$ & & $2.66^{* * *}$ & $1.53-4.64$ & $6.12^{* * *}$ & $2.40-15.62$ & & $2.03^{* * *}$ & $1.36-3.05$ & $4.06^{* * *}$ & $2.05-8.05$ & \\
\hline $45-54$ & 1.31 & $0.70-2.48$ & 2.47 & $0.88-6.94$ & & $2.89 * * *$ & $1.65-5.09$ & $3.29 *$ & $1.24-8.70$ & & $2.01^{* * *}$ & $1.33-3.03$ & $3.12^{* * *}$ & $1.59-6.28$ & \\
\hline $55-64$ & 1.69 & $0.91-3.12$ & $3.12^{*}$ & $1.13-8.60$ & & $2.26^{* *}$ & $1.32-3.86$ & $2.98^{*}$ & $1.15-7.75$ & & $1.99 * * *$ & $1.34-2.96$ & $3.00^{* * *}$ & $1.49-6.103$ & \\
\hline Education level & & & & & 0.072 & & & & & 0.292 & & & & & 0.116 \\
\hline Tertiary & 1.00 & & 1.00 & & & 1.00 & & 1.00 & & & 1.00 & & 1.00 & & \\
\hline Primary & 1.68 & $0.82-3.42$ & 1.06 & $0.43-2.64$ & & 0.42 & $0.11-1.56$ & 0.54 & $0.12-2.43$ & & 1.26 & $0.70-2.27$ & 1.05 & $0.51-2.15$ & \\
\hline Secondary & $2.06^{*}$ & $1.08-3.92$ & 1.87 & $0.85-4.08$ & & 0.44 & $0.12-1.69$ & 0.63 & $0.14-2.73$ & & 1.43 & $0.82-2.51$ & 1.49 & $0.76-2.91$ & \\
\hline Marital status & & & & & 0.041 & & & & & 0.797 & & & & & 0.126 \\
\hline Divorced & 1.00 & & 1.00 & & & 1.00 & & 1.00 & & & 1.00 & & 1.00 & & \\
\hline Single & 1.66 & $0.99-2.78$ & $2.10^{*}$ & $1.03-4.28$ & & 0.95 & $0.60-1.50$ & 1.35 & $0.72-2.53$ & & 1.23 & $0.88-1.72$ & $1.69^{*}$ & $1.06-2.69$ & \\
\hline Married & 1.24 & $0.74-2.07$ & 1.09 & $0.53-2.26$ & & 1.02 & $0.68-1.53$ & 1.28 & $0.72-2.30$ & & 1.10 & $0.81-1.51$ & 1.20 & $0.77-1.88$ & \\
\hline Occupation & & & & & $<0.001$ & & & & & $<0.001$ & & & & & $<0.001$ \\
\hline Less skilled & 1.00 & & 1.00 & & & 1.00 & & 1.00 & & & 1.00 & & 1.00 & & \\
\hline Skilled & 0.84 & $0.54-1.32$ & $1.69^{*}$ & $1.00-2.85$ & & 1.23 & $0.73-2.06$ & $2.70 * * *$ & $1.51-4.83$ & & 0.99 & $0.71-1.39$ & $2.07^{* * *}$ & $1.41-3.05$ & \\
\hline Location & & & & & & & & & & & & & & & $<0.001$ \\
\hline Rural & & & & & & & & & & & 1.00 & & 1.00 & & \\
\hline Urban & & & & & & & & & & & $1.67^{* * *}$ & $1.31-2.13$ & 1.20 & $0.87-1.65$ & \\
\hline
\end{tabular}

OR odds ratios, $\mathrm{Cl}$ confidence interval; ${ }^{*} p<0.05 ;{ }^{* *} p<0.01 ;{ }^{* * *} p<0.001 ;{ }^{\text {a }}$ Odds ratios adjusted for all variables in the table; bold $p=$ significant borderline 
Although it is difficult to interpret these conflicting results, South Africa could be described as a country in transition, and consequently there are currently high levels of infrastructure development, for which men are typically employed and often requires high levels of vigorous activity. Similarly, African cultural influence may make women more likely to be employed in domestic work such as cleaning and organizing households, which may mean they walk less, particularly in black townships areas [32]. Generally in African culture, women have hobbies that tend to keep them at home while men tend to engage in more physical recreational activities [32]. Based on these cultural differences, physical inactivity poses a major health risk to the South African women and with the projected increase in health risk to over $65 \mathrm{~s}$, an increase in morbidity and mortality in these areas is expected. Hence, necessary interventions need to be implemented, among women through all age groups at societal level [33].

Our study showed that PA decreased with age, in accordance with previous studies [34, 35]. A similar study found that the volume of sedentary behaviour increased, whereas ambulatory activity [36] and recreational activity [37] decreased with age. Due to the fact that studies use different measures and definitions, direct comparisons are not possible. For example, vigorous activity have been reported to decrease with age, whereas moderate intensity activity increase from ages 13 to 27 years [38]. Furthermore, the relationship can be affected by the effect of various confounding factors such as genetic, cultural, socio-economic, nutritional factors and inactivity [39]. These act through reduction of the functional abilities, strength, and ambulation associated with increased age-related diseases. As a result, the relationship between physical activity and healthy ageing among adults still remains complex, and physical activity levels must be taken into account in ageing studies [39].

Level of education has also been associated with PA [40]. Similarly, results in this study showed that in urban areas, participants who had reached secondary level education were twice more likely to engage in moderate PA than those with tertiary education. In rural areas, participants with primary education tended to be the least likely group to engage in moderate PA. These results are comparable to another study which found the level of education was associated with the likelihood of walking [41]. Thus, people with less education may be more likely to walk or cycle than the highly educated, possibly because the latter may own a car, with the associated reduction in physical inactivity. It is also likely that less well educated people may be employed in jobs that are more physically demanding, while they also have insufficient money and time to engage in leisure-time PA. Contrarily, people at a higher educational level may have more sedentary jobs, but may engage more in leisuretime PA that those less well educated because they are more aware of it and its associated health benefits [42].

Cross-sectional studies report mixed results concerning the relationship between marital status and PA, although it is often an inverse relationship, where married individuals are less physically active than those who are unmarried [43]. This study showed that, both in the urban site and overall, a higher proportion of single participants engaged in moderate-to-vigorous PA than those who were divorced or separated, and comparable results to these were reported by a study in Lebanon [44]. There are however also reports that show married people as being more active than the single people [45], and a study based in Nigeria found a positive association between being married and reaching sufficient PA levels [18]. However, in this study, being married was not a determinant factor for PA.

Contrasting results in studies of the relationship between marital status and PA could be a consequence of contrasting variables. For instance, cultural expectations of married African adults, especially men, may differ and men may be expected to be the primary earners [18] but this may not be true in all countries, such as South Africa.

Likewise, this study noted that participants with skilled jobs were more likely to engage in vigorous PA than less skilled (or homemakers). Similarly, a study in Mexico showed that a higher percentage of adults working in agriculture and fishing were in a higher activity level category than those in lower-intensity occupational activities, the latter also having a greater proportion of participants in low and moderate activity levels [46]. A study in Australia, however, showed those participants in the lower strata of occupations to be less likely to report participation in vigorous PA sufficient to achieve cardiorespiratory fitness [47]. Most of sub-Saharan African countries, particularly those undergoing rapid developments, are in the midst of demographic and epidemiologic transitions. These developmental processes bring about changes in the social capital of societies, change working patterns and lifestyles contributing to reduction in physical activity levels [48].

\section{Limitations and strengths}

Our study has some limitations. Its cross-sectional design did not allow for the investigation of causal relationship among characteristics. This study was restricted to adults only, in two provinces of South Africa, and its findings may not be applicable countrywide. Finally, another limiting factor of this study was that PA was assessed with a version of IPAQ, a self-report measure associated with overestimation of PA levels [45]. Nevertheless, this study was based on a large cohort of urban 
and rural South Africans, primarily of African descent which was assessed using a standardized method for surveying risk factors for chronic diseases. The study adds to previous reports by providing determinants and prevalence of PA levels in an urban and rural setting in South Africa. However, future studies aiming at monitoring of the exposure to PA should consider conducting objective assessment of PA in order to validate PA in urban and rural communities.

\section{Conclusion}

Culturally or community tailored intervention to promote physical activity should target individuals at an early age, those with primary, tertiary education, married and divorced and rural residents in South Africa. The current study indicates that if no effective public health approach or social economic plans are implemented, further decrease in physical activity will lead to high risk of developing major chronic diseases among South Africans. Studies using objective assessment of physical activity are needed to confirm these findings.

\section{Abbreviations}

BMI: Body mass index; IPAQ: International Physical Activity Questionnaire; METs: Metabolic rate; NCDs: Non-communicable diseases; PA: Physical activity; PHRI: Population Health Research Institute; PURE: Prospective Urban and Rural epidemiology study; USA: United Sates of America;

UWC: University of the Western Cape

\section{Acknowledgements}

The author gratefully acknowledges the Population Health Research Institute, Hamilton Health Sciences and McMaster University, Hamilton Canada and the South African Medical Research Council for providing access to these data. Opinions, findings, conclusions and recommendations expressed are those of the authors and the funders accept no liability whatsoever in this regard.

\section{Funding}

This study was partially supported by Social Innovation in Public Health Impulse fellowship programme for analysis, interpretation of data, transport and accommodation.

\section{Availability of data and materials}

Please contact author for data requests.

\section{Authors' contributions}

PM, APK and EVL were involved in the conception and design. PM conducted the analysis. PM and APK were involved with interpretation and wrote the first draft. PM, APK, ADV and TP were involved with drafting, revising and final approval. All authors read and approved the final manuscript.

\section{Competing interests}

The authors declare that they have no competing interests.

\section{Consent for publication}

Not applicable.

\section{Ethics approval and consent to participate}

The study was conducted according to the Helsinki principles [49]. The Senate Higher Degrees committee, Research Committees of the University of the Western Cape (UWC), South Africa and the Population Health Research Institute (PHRI) in Canada approved this study (Registration \#13/6/18).

\section{Author details}

'University of Western Cape, School of Public Health, Robert Sobukwe Road, Bellville, Cape Town 7535, South Africa. ${ }^{2}$ Non-communicable disease Unit, South African Medical Research Council, Francie van Zijl Drive, Parowvallei, P.O. Box 190707505 Tygerberg, Cape Town, South Africa. ${ }^{3}$ Division of Exercise Science and Sports Medicine, Department of Human Biology, Faculty of Health Sciences, University of Cape Town, P.O. Box 115, Newlands 7725, Cape Town, South Africa.

Received: 15 September 2016 Accepted: 18 November 2016

Published online: 29 December 2016

\section{References}

1. Nelson ME, Rejeski WJ, Blair SN, Duncan PW, Judge JO, King AC, et al. Physical activity and public health in older adults: recommendation from the American College of Sports Medicine and the American Heart Association. Circulation. 2007;116(9):1094-105.

2. Haley C, Andel R. Correlates of physical activity participation in communitydwelling older adults. J Aging Phys Act. 2010;18(4):375-89.

3. Hallal PC, Andersen LB, Bull FC, Guthold R, Haskell W. Global physical activity levels: surveillance progress, pitfalls, and prospects. Lancet. 2012; 6736:247-57.

4. Lee I-M, Shiroma EJ, Lobelo F, Puska P, Blair SN, Katzmarzyk PT. Effect of physical inactivity on major non-communicable diseases worldwide: an analysis of burden of disease and life expectancy. Lancet. 2012;380(9838): 219-29.

5. World Health Organisation. Global Recommendations on Physical Activity for Health. Geneva: WHO Press; 2010.

6. Joubert J, Norman R, Lambert EV, Groenewald P, Schneider M, Bull F, Btadshwa D. Estimating the burden of disease attributable to physical inactivity in South Africa in 2000. S Afr Med J. 2007;97(8): 725-31.

7. Jemmott JB, Jemmott LS, Ngwane Z, Zhang J, Heeren GA, Icard LD, et al. Theory-based behavioral intervention increases self-reported physical activity in South African men: a cluster-randomized controlled trial. Prev Med. 2014;64:114-20.

8. Guthold R, Louazani SA, Riley LM, Cowan MJ, Bovet P, Damasceno A, et al, Physical activity in 22 African countries: results from the World Health Organization STEP wise approach to chronic disease risk factor surveillance. Am J Prev Med. 2011;41(1):52-60.

9. Phaswana-Mafuya N, Peltzer K, Chirinda W, Musekiwa A, Kose Z. Sociodemographic predictors of multiple non-communicable disease risk factors among older adults in South Africa. Glob Health Action. 2013;6:20680.

10. Van Zyl S, Van der Merwe LJ, Walsh CM, Groenewald AJ, Van Rooyen FC. Risk-factor profiles for chronic diseases of lifestyle and metabolic syndrome in an urban and rural setting in South Africa. African J Prim Heal Care Fam Med. 2012;4(1):1-11.

11. Wilcox S, Castro C, King AC, Housemann R, Brownson RC. Determinants of leisure time physical activity in rural compared with urban older and ethnically diverse women in the United States. J Epidemiol Community Health. 2000;54(9):667-72.

12. Martin SL, Kirkner GJ, Mayo K, Matthews CE, Durstine JL, Hebert JR. Urban, rural, and regional variations in physical activity. J Rural Health. 2005;21(3): 239-44.

13. Ojiambo RM, Easton C, Casajús JA, Konstabel K, Reilly JJ, Pitsiladis Y. Effect of urbanization on objectively measured physical activity levels, sedentary time, and indices of adiposity in Kenyan adolescents. J Phys Act Heal. 2012; 9:115-23.

14. Peer N, Bradshaw D, Laubscher R, Steyn N, Steyn K. Urban/rural and gender differences in tobacco and alcohol use, diet and physical activity among young black South Africans between 1998 and 2003. Glob Health Action. 2013;6:19216.

15. Shisana O, Labadarios D, Rehle T, Simbayi L, Zuma K, Dhansay ARP, et al. South African National Health and Nutrition Examination Survey (SANHANES-1). Cape Town: HSRC Press; 2013.

16. Haskell WL, Lee I-M, Pate RR, Powell KE, Blair SN, Franklin BA, et al. Physical activity and public health: updated recommendation for adults from the American College of Sports Medicine and the American Heart Association. Med Sci Sports Exerc. 2007;116(9):1081-93. 
17. Parks SE, Housemann RA, Brownson RC. Differential correlates of physical activity in urban and rural adults of various socioeconomic backgrounds in the United States. J Epidemiol Community Health. 2003;57(1):29-35.

18. Oyeyemi AL, Oyeyemi AY, Jidda ZA, Babagana F. Prevalence of physical activity among adults in a Metropolitan Nigerian City: a cross-sectional study. J Epidemiol. 2013;23(3):169-77.

19. Teo K, Chow CK, Vaz M, Rangarajan S, Yusuf S. The Prospective Urban Rural Epidemiology [PURE] study : examining the impact of societal influences on chronic noncommunicable diseases in low-middle and high-income countries. Am Heart J. 2009;185(1):1-7.

20. Chow CK, Lock K, Madhavan M, Corsi DJ, Gilmore AB, Subramanian SV, et al. Environmental Profile of a Community's Health (EPOCH). An instrument to measure environmental determinants of cardiovascular health in five countries. PLoS One. 2010;5(12), e14294. doi:10.1371/ journal.pone.0014294.

21. Bauman A, Bull F, Chey T, Craig CL, Ainsworth BE, Sallis JF, et al. The International Prevalence Study on Physical Activity: results from 20 countries. Int J Behav Nutr Phys Act. 2009;6:21. doi:10.1186/1479-5868-6-21.

22. Saelens BE, Sallis JF. Neighborhood Environment Walkability Survey (NEWS) \& Neighborhood Environment Walkability Survey-Abbreviated (NEWS-A). Measurement Instrument Database for the Social Science; 2012. Retrieved from http://www.midss.org.

23. Schlomer GL, Bauman S, Card NA. Best practices for missing data management in counseling psychology. J Couns Psychol. 2010;57(1):1-10.

24. Gradidge PJ-L, Crowther NJ, Chirwa ED, Norris SA, Micklesfield LK. Patterns, levels and correlates of self-reported physical activity in urban black Soweto women. BMC Public Health. 2014;14(1):934. doi:10.1186/ 1471-2458-14-934.

25. Assah F, Mbanya JC, Ekelund U, Wareham N, Brage S. Patterns and correlates of objectively measured free-living physical activity in adults in rural and urban Cameroon. J Epidemiol Community Heal. 2015;0:1-8. doi:10.1136/jech-2014-205154.

26. Craig E, Bland R, Reilly J. Objectively measured physical activity levels of children and adolescents in rural South Africa: high volume of physical activity at low intensity. Appl Physiol Nutr Metab. 2013;38(1):81-4.

27. Padrão P, Damasceno A, Silva-Matos C, Prista A, Lunet N. Physical activity patterns in Mozambique: urban/rural differences during epidemiological transition. Prev Med. 2012;55(5):444-9.

28. Heesch KC, van Uffelen JGZ, Hill RL, Brown WJ. What do IPAQ questions mean to older adults? Lessons from cognitive interviews. Int J Behav Nutr Phys Act. 2010;7:35.

29. Bull FC, Armstrong TP, Dixon T, Ham S, Neiman A, Pratt M. Physical inactivity. http://apps.who.int/publications/cra/chapters/volume1/0729-0882. pdf. Accessed 17 Oct 2016.

30. Romo-Perez V, Schwingel A, Chodzko-Zajko W. Walking among older adults in Spain: frequency and gender roles. Int Sport J. 2012;13(4):180-9.

31. Kanyoni M, Phillips JS. Factors associated with physical activity levels among older adults in selected institutions in Rwanda. J Commun H Sci. 2009;4(1): 8-14.

32. Walter CM, Randt RDU. Socio-cultural barriers to physical activity among black isixhosa speaking professional women in the nelson mandela metropolitan municipality. S Afr J Res Sport Phys Educ Recreation. 2011; 33(2):143-55.

33. Strydom GL. Physical activity, health and well-being - A strategic objective of the National Sport and Recreation Plan (NSRP) of South Africa. S Afr J Res Sport Phys Educ Recreation. 2013;19(4):980-92.

34. Milanović Z, Pantelić S, Trajković N, Sporiš G, Kostić R, James N. Age-related decrease in physical activity and functional fitness among elderly men and women. Clin Interv Aging. 2013:8:549-56.

35. Mummery WK, Kolt G, Schofield G, McLean G. Associations between physical activity and other lifestyle behaviors in older New Zealanders. J Phys Act Health. 2007;4(4):411-22.

36. Godfrey A, Lord S, Galna B, Mathers JC, Burn DJ, Rochester L. The association between retirement and age on physical activity in older adults. Age Ageing. 2014;43:386-93

37. Swenson CJ, Marshall JA, Mikulich-Gilbertson SK, Baxter J, Morgenstern N. Physical activity in older, rural, Hispanic, and non-Hispanic white adults. Med Sci Sports Exerc. 2005;37(6):995-1002.

38. van Mechelen W, Twisk JW, Post GB, Snel J, Kemper HC. Habitual activity of young people: the Amsterdam Growth and Health Study. Med Sci Sports Exerc. 2000;32:1610-6.
39. Lazarus NR, Harridge SDR. Exercise, physiological function, and the selection of participants for aging research. J Gerontol A Biol Sci Med Sci. 2010;65A: 854-7.

40. Pollock RD, Carter S, Velloso CP, Duggal NA, Lord JM, Lazarus NR, Harridge SDR. An investigation into the relationship between age and physiological function in highly active older adults. J Physiol. 2015;593(3):657-80.

41. Jurakić D, Pedišić Ž, Andrijašević M. Physical activity of Croatian population: cross-sectional study using International Physical Activity Questionnaire. Croat Med J. 2009;50(2):165-73.

42. Nomaguchi KM, Bianchi SM. Exercise time: gender differences in the effects of marriage, parenthood, and employment. J Marriage Fam. 2004;66:413-30.

43. Al-Tannir M, Kobrosly S, Itani T, El-Rajab M, Tannir S. Prevalence of physical activity among Lebanese adults: a cross-sectional study. J Phys Act Health. 2009;6(3):315-20.

44. Zimmermann E, Ekholm O, Gronbaek M, Curtis T. Predictors of changes in physical activity in a prospective cohort study of the Danish adult population. Scand J Public Heal. 2008;36(3):235-41.

45. Ortiz-Hernández L, Ramos-lbáñez N. Sociodemographic factors associated with physical activity in Mexican adults. Public Health Nutr. 2010;13(7):1131-8.

46. Salmon J, Owen N, Bauman A, Schmitz MK, Booth M. Leisure-time, occupational, and household physical activity among professional, skilled, and less-skilled workers and homemakers. Prev Med. 2000;30(3):191-9.

47. Atkinson K, Lowe S, Moore S. Human development, occupational structure and physical inactivity among 47 low and middle income countries. Prev Med Rep. 2016:3:40-5.

48. Rzewnicki R, Vanden Auweele Y, De Bourdeaudhuij I. Addressing overreporting on the International Physical Activity Questionnaire (IPAQ) telephone survey with a population sample. Public Health Nutr. 2003;6(3): 299-305.

49. WHO. World Medical Association Declaration of Helsinki. Bull World Heal Organ. 2001;79(4):373-4.

\section{Submit your next manuscript to BioMed Central and we will help you at every step:}

- We accept pre-submission inquiries

- Our selector tool helps you to find the most relevant journal

- We provide round the clock customer support

- Convenient online submission

- Thorough peer review

- Inclusion in PubMed and all major indexing services

- Maximum visibility for your research

Submit your manuscript at www.biomedcentral.com/submit 